\title{
Degradation of $17 \alpha$-ethinylestradiol by ozonation - Identification of the by-products and assessment of their estrogenicity and toxicity
}

\author{
Simone Larcher ${ }^{\mathrm{a}}$, Geraldine Delbès ${ }^{\mathrm{b}}$, Bernard Robaire ${ }^{\mathrm{b}, \mathrm{c}}$, Viviane Yargeau ${ }^{\mathrm{a}, *}$ \\ a Department of Chemical Engineering, McGill University, Montréal, Québec, Canada \\ b Department of Pharmacology and Therapeutics, McGill University, Montréal, Québec, Canada \\ c Department of Obstetrics and Gynecology, McGill University, Montréal, Québec, Canada
}

\section{A R T I C L E I N F O}

\section{Article history:}

Received 15 June 2011

Accepted 26 September 2011

Available online 4 November 2011

\section{Keywords:}

$17 \alpha$-Ethinylestradiol (EE2)

$17 \beta$-Estradiol (E2)

Ozone $\left(\mathrm{O}_{3}\right)$

Estrogenicity

Toxicity

Testosterone

\begin{abstract}
A B S T R A C T
The presence of the synthetic estrogen $17 \alpha$-ethinylestradiol (EE2) in waters at low levels is a concern due to its ability to act as an endocrine disruptor. Ozone $\left(\mathrm{O}_{3}\right)$ is commonly used in water treatment and reacts with EE2 to form by-products having characteristics that are mostly unknown. The aim of this study was to identify the byproducts of E2 and EE2 ozonation and determine their estrogenicity and toxicity relative to the parent compound. Ozonation by-products were identified via LC-MS analysis. The estrogenicity was measured using the YES assay, and toxicity was determined by monitoring effects on histology of fetal rat testes and testosterone secretion by these tissues. Two EE2 by-products were identified with open phenolic ring structures (masses 302 and $344 \mathrm{u}$ ). The Yeast Estrogen Screening (YES) assay showed a decreased but incomplete removal of estrogenicity after ozonation of EE2. Histological analysis of fetal testes revealed that neither E2 nor EE2, with or without ozonation, had any effect on seminiferous cord formation; however, a remarkable negative effect on testosterone secretion was observed, with EE2 by-products after ozonation showing the most rapid and extensive inhibition. These results show that the removal of $\mathrm{EE} 2$ via reaction with $\mathrm{O}_{3}$ resulted in the formation of by-products that are less estrogenic (as demonstrated by the YES assay), but have a greater negative impact on testosterone secretion. Thus, the disappearance of the parent compound is not a sufficient endpoint, as the by-products created may be more toxic. Care should be taken when implementing oxidation applications such as ozone during waste water treatment.
\end{abstract}

@ 2011 Elsevier Ltd. All rights reserved.

\section{Introduction}

Due to the common use of oral contraceptives (Cavallucci, 2007), their excretion and inefficient removal during conventional wastewater treatment, $17 \alpha$-ethinylestradiol (EE2) has been detected in surface waters and wastewater effluents at low levels (up to $62 \mathrm{ng} / \mathrm{L}$ ) (Cicek et al., 2007; Gomes et al., 2003; Huber et al., 2004; Joss et al., 2005; Kolpin et al., 2002; Lai et al., 2002; Miège et al., 2009; Petrovic et al., 2002; Ternes, 1998; Ternes et al., 1999a, 1999b). EE2 can act as an endocrine disruptor on aquatic organisms and mammals through environmental exposures or the food chain and induce reproductive disorders (Aravindakshan et al., 2004; Lange et al., 2009; Vos et al., 2000). For example, it has been shown that adult African clawed male toads exposed to EE2 $\left(10^{-8} \mathrm{M}, \sim 3 \mu \mathrm{g} / \mathrm{L}\right)$ exhibited decreased seminiferous tubule mean diameter and occurrence of small oocytes in the testis, suggesting feminization (Cevasco et al., 2008). The hypothesis that estrogen-like molecules could impair adult male fertility

\footnotetext{
* Corresponding author at: Department of Chemical Engineering, McGill University, 3610 University Street, Montréal, Québec, Canada H3A 2B2. Tel.: +1 514398 2273; fax: + 15143986678 .

E-mail address: viviane.yargeau@mcgill.ca (V. Yargeau).
}

by acting during gonadal development (Sharpe and Skakkebaek, 1993) is well supported by animal studies. Exposure during development (from gestational day 7 to postnatal day 8) to oral micromolar doses of EE2 permanently disrupted the reproductive tract of male rats (Howdeshell et al., 2008). We have also previously shown that ex vivo exposure of the fetal rat testis to exogenous $17 \beta$-estradiol (E2) or diethylstilbestrol (DES) induced a time and dose dependent negative impact on gonocyte number and testosterone secretion (Delbes et al., 2007). Thus, the presence of estrogenic compounds in surface waters has become a major concern.

Ozone $\left(\mathrm{O}_{3}\right)$ is gaining popularity as a disinfectant during wastewater treatment, and it has been demonstrated that it is capable of removing compounds of emerging concern such as EE2 (Esplugas et al., 2007; Huber et al., 2003, 2005; Nakada et al., 2007; Reungoat et al., 2010; Schwarzenbach et al., 2006; Ternes et al., 2003). Since the structure of EE2 contains an aromatic ring with a phenolic group, and $\mathrm{O}_{3}$ is a selective oxidant toward these moieties (Huber et al., 2004), the reaction between EE2 and $\mathrm{O}_{3}$ occurs very quickly with rate constants estimated experimentally to range from $1.83 \times 10^{5}$ to $3.65 \times 10^{9} \mathrm{M}^{-1} \mathrm{~s}^{-1}$; this is similar for all estrogens including the naturally occurring E2 (Deborde et al., 2005). Past studies investigating the removal of EE2 by $\mathrm{O}_{3}$ ( $54 \%$ to $>99 \%$ removal) and the formation 
of by-products show conflicting results. The by-products' identification and the presence of an intact phenolic ring, thought to provide the estrogenic activity (Huber et al., 2004), are unclear (Guedes Maniero et al., 2008; Lee et al., 2008; Vieira et al., 2010; Zhang et al., 2006). Some studies have also shown that the estrogenic activity of EE2-containing waters is reduced after $\mathrm{O}_{3}$ application from $13 \%$ to less than $1 / 200$ th of the original amount (Guedes Maniero et al., 2008; Huber et al., 2004; Lee et al., 2008).

The objectives of the present study are to characterize the reaction of $\mathrm{O}_{3}$ with $\mathrm{E} 2$ and EE2 at different $\mathrm{pH}$, to identify the chemical structure of ozonated by-products and to investigate their estrogenicity and toxicity on rat fetal testes.

\section{Materials and methods}

\subsection{Chemicals and reagents}

The estrogens 17ß-estradiol (E2) (CAS 50-28-2, purity 98\%) and $17 \alpha$-ethinylestradiol (EE2) (CAS 57-63-6, purity 98\%) as well as formic acid, sodium hydroxide and ammonium acetate were purchased from Sigma-Aldrich (Oakville, Ontario, Canada). The reagent alcohol ( $\geq 90 \%$ ethanol), acetone, and acetonitrile (ACN) were purchased from Fisher Scientific (Oakville, Ontario, Canada). Deuterated-EE2 (17 $\alpha$-ethinylestradiol-2,4,16,16- $\mathrm{d}_{4}$, product number D-4319) was obtained from C/D/N Isotopes Inc. (Pointe-Claire, Quebec, Canada).

The estrogen solutions used were made by diluting concentrated stock solutions ( $1 \mathrm{~g} / \mathrm{L}$ E2 or EE2 made in ethanol) in reverse osmosis (RO) water. When necessary, the $\mathrm{pH}$ of the solutions was adjusted using formic acid or sodium hydroxide. All solutions used for HPLC analysis were vacuum filtered using $0.2 \mu \mathrm{m}$ nylon filters and degassed for $30 \mathrm{~min}$.

Stock $\mathrm{O}_{3}$ solutions were made by sparging $\mathrm{O}_{3}$ gas produced by an Ozomax generator and a pure oxygen gas feed through RO water contained in a gas-washing bottle chilled to $2{ }^{\circ} \mathrm{C}$ on ice. The dissolved $\mathrm{O}_{3}$ concentration was determined spectrophotometrically by measuring the absorbance at $258 \mathrm{~nm}\left(\varepsilon=2950 \mathrm{M}^{-1} \mathrm{~cm}^{-1}\right)$ (Bader and Hoigné, 1981). The $\mathrm{O}_{3}$ stock solution was added to the E2 and EE2 solutions in order to achieve the desired $\mathrm{O}_{3}$ dose.

Culture media (DMEM/Hamf12 without phenol red) was prepared using $1 \mathrm{~L}$ of water containing the products to be tested (Table 1 ). Briefly, powder media was dissolved in $1 \mathrm{~L}$ of water supplemented with $1.2 \mathrm{~g}$ of sodium bicarbonate and the $\mathrm{pH}$ was adjusted to 7.2. $200 \mathrm{~mL}$ was further sampled and supplemented with $15 \mathrm{mM}$ of Hepes and $0.04 \mathrm{mg} / \mathrm{mL}$ of gentamycin, filtered though a $0.22 \mu \mathrm{m}$ membrane under vacuum and stored at $4{ }^{\circ} \mathrm{C}$.

\subsection{Solid phase extraction (SPE)}

The estrogen solutions were concentrated using Bond Elut C18 cartridges (Varian, $500 \mathrm{mg} / 6 \mathrm{~mL}$ ) and an automated SPE system (Gilson GX-271 ASPEC). The cartridges were conditioned sequentially with $6 \mathrm{~mL}$ each acetone, reagent alcohol, and RO water ( $\mathrm{pH} 7.5$ ), followed immediately by the E2 or EE2 solution being concentrated $(10 \mathrm{~mL} / \mathrm{min})$. The estrogens were then eluted from the cartridge using $6 \mathrm{~mL}$ of reagent grade ethanol. The eluted samples were dried completely in

Table 1

Summary of experimental conditions for the organ culture.

\begin{tabular}{ll}
\hline Control media & Treatment media \\
\hline EtOH $(0.005 \%)$ & EE2 $50 \mu \mathrm{g} / \mathrm{L}$ \\
EtOH $(0.005 \%)+50 \mu \mathrm{g} / \mathrm{L} \mathrm{O}_{3}$ & EE2 $50 \mu \mathrm{g} / \mathrm{L}+\mathrm{O}_{3} 50 \mu \mathrm{g} / \mathrm{L}$ \\
EtOH $(0.05 \%)$ & EE2 $500 \mu \mathrm{g} / \mathrm{L}$ \\
EtOH $(0.05 \%)+500 \mu \mathrm{g} / \mathrm{L} \mathrm{O}_{3}$ & EE2 $500 \mu \mathrm{g} / \mathrm{L}+\mathrm{O}_{3} 500 \mu \mathrm{g} / \mathrm{L}$ \\
EtOH $(0.005 \%)$ & E2 $50 \mu \mathrm{g} / \mathrm{L}$ \\
\hline
\end{tabular}

approximately $2.5 \mathrm{~h}$ using a Thermo Scientific Speed Vac Concentrator (Savant SPD131DDA) coupled with a refrigerated vapor trap (RVT4104) $\left(50{ }^{\circ} \mathrm{C}, 1 \mathrm{Torr}, \mathrm{ramp}=30 \mathrm{Torr} / \mathrm{min}\right)$. The dried samples were reconstituted in $20 \%(\mathrm{v} / \mathrm{v})$ alcohol solution prior to HPLC analysis.

\subsection{HPLC analysis}

E2, EE2 and the $\mathrm{O}_{3}$ by-products were determined using an Agilent 1200 HPLC equipped with a Zorbax Eclipse Plus C18 column $(150 \times 4.6 \mathrm{~mm}, 3.5 \mu \mathrm{m})$ and a diode array detector using a detection wavelength of $279 \mathrm{~nm}$. A fraction collector was used to collect samples of by-product peaks separately. The HPLC operating conditions were: mobile phase $\mathrm{A}=20 \mathrm{mM}$ ammonium acetate $(\mathrm{pH}=2.8)$; mobile phase $\mathrm{B}=\mathrm{ACN}$; gradient $=30 \% \mathrm{ACN}(0-5 \mathrm{~min}), 50 \% \mathrm{ACN}$ (5-10 min), $70 \%$ ACN (10-15 min); flow rate $=1 \mathrm{~mL} / \mathrm{min}$; injection volume $=25 \mu \mathrm{L}$; temperature $=28^{\circ} \mathrm{C}$. The limit of detection (LOD) of the HPLC method was calculated to be $60 \mu \mathrm{g} / \mathrm{L}$; however, taking into account the SPE concentration $(200 \times)$ of the samples, the overall LOD was $0.3 \mu \mathrm{g} / \mathrm{L}$.

\subsection{Identification of ozone by-products}

The by-products present in the ozonated EE2-containing waters and in the by-product peaks collected as fractions were identified using a LC-MS system composed of an Agilent 1200 LC system equipped with a Zorbax Extend C18 column $(50 \times 2.1 \mathrm{~mm}, 1.8 \mu \mathrm{m})$ and an Agilent 6530 quadrupole-time of flight mass spectrometer (QqTOFMS). The LC operating conditions were: mobile phase $\mathrm{A}=$ water; mobile phase $\mathrm{B}=\mathrm{ACN}$; $\mathrm{ACN}$ gradient $=30 \%(0-0.5 \mathrm{~min})$, 50\% (0.6-1.3 min), 70\% (1.4-2.1 min), 97\% (2.2-3.2 min), 30\% (3.3$10 \mathrm{~min}$ ); flow rate $=0.5 \mathrm{~mL} / \mathrm{min}$; injection volume $=10 \mu \mathrm{L}$. Ionization was performed in the negative mode using an atmospheric pressure chemical ionization (APCI) source. APCI conditions were the following: nitrogen gas $\left(\mathrm{N}_{2}\right)$, vaporizer temperature $=350{ }^{\circ} \mathrm{C}$, drying gas $\left(\mathrm{N}_{2}\right)$ flow $=8 \mathrm{~L} / \mathrm{min}$, nebulizer $=45 \mathrm{psig}$, fragmentor $=150 \mathrm{~V}$, skimmers $=65 \mathrm{~V}$, capillary voltage $=3500 \mathrm{~V}$ and corona needle voltage $=4 \mu \mathrm{A}$. The QqTOFMS was operated in the $4 \mathrm{GHz}$ High Resolution with low mass range mode $(1700 \mathrm{~m} / \mathrm{z})$. Acquisition was performed in the MS (TOF only) mode at a rate of $8 \mathrm{spectra} / \mathrm{s}$. Data analysis was done using an Agilent MassHunter Qual B.03.01, and the products were verified using a deuterated ethinylestradiol (EE2-d4).

\subsection{Yeast Estrogen Screening (YES) assay}

The YES assay was conducted as previously described (Routledge and Sumpter, 1996) with minor modifications. The yeast strain was provided by C. Metcalfe (Trent University, Peterborough, Ontario, Canada) and the 96-well plates were incubated for 4 days before measuring the absorbance at $540 \mathrm{~nm}$ with a correction for turbidity at $630 \mathrm{~nm}$ (Metcalfe et al., 2001) using a BIO RAD Benchmark Plus equipped with Microplate Manager 5.2.1. The degree of color change induced by successive dilutions of the test chemicals provided a measure of their estrogenic potency. The validity of the assay was confirmed by the response of the reference compound used (E2) that showed a median effective concentration (EC50) of $1.5 \times 10^{-10} \mathrm{M}$ $(n=13)$. This EC50 is within the range of previously published values (Balsiger et al., 2010; Guedes Maniero et al., 2008). Replicates of the test compounds (EE2-containing waters before and after $\mathrm{O}_{3}$ treatment and the by-product peaks collected as fractions) were evaporated and re-dissolved in ethanol and tested ( $n=6$ to 7 ) in a range of 12 dilutions (1:2) with a row of ethanol blanks and E2 standards in each plate (Supplemental Fig. 1).

\subsection{Organ culture}

Sprague Dawley rats were housed on a 12L:12D cycle with food and water provided ad libitum. All animal studies were conducted 
in accordance with the guidelines outlined in A Guide to the Care and Use of Experimental Animals prepared by the Canadian Council on Animal Care. Virgin Sprague Dawley females were mated with males overnight and considered as pregnant $(0.5 \mathrm{dpc})$ when vaginal sperm was detected the next morning. At 15.5 days of gestation, females were asphyxiated with $\mathrm{CO}_{2}$ and the uteri horns were removed. Fetuses were removed from the uterus and testes were dissected out. Organ cultures were done as previously described (Livera et al., 2006) in 24 well plates (Corning, NY). One testis of each fetus was placed on a filter floating on $400 \mu \mathrm{L}$ of control medium while the other one was placed on a filter floating on $400 \mu \mathrm{L}$ of medium prepared with water containing the factors being tested (Table 1 ). The media were changed every $24 \mathrm{~h}$ and the culture was maintained for $72 \mathrm{~h}$. Media (see description of preparation in Section 2.1) were stored at $-20{ }^{\circ} \mathrm{C}$ until its use in the testosterone assay.

\subsection{Testosterone assay}

Testosterone concentrations in the culture media were measured using a testosterone ELISA kit following the manufacturer's protocol (IBL Immuno-Biological Laboratories, Hamburg, Germany). Each sample was run in duplicate.

\subsection{Histology-immunohistochemistry}

At the end of the culture period, testes were fixed for $2 \mathrm{~h}$ in Saint Mary's solution (95\% ethanol, $1 \%$ acetic acid), embedded in paraffin, and cut into $5 \mu \mathrm{m}$ sections for histological analysis. Serial sections were mounted on slides, deparaffinized, rehydrated, and stained with Hematoxylin-Eosin. The gonocytes were identified by immunocytochemical detection of HSP90 (BD Biosciences - dilution 1:200) as previously described (Culty, 2009).

\subsection{Statistical analysis}

All values are shown as means \pm SEM. To measure the impact of treatment over time in the organ culture system, we performed a 2way ANOVA analysis using GraphPad Prism version 5.0 for windows (GraphPad software, San Diego, CA). Post-hoc Bonferroni tests were performed to assess the treatment significance compared to controls at each time point. The YES assay results were analyzed using a 4 parameter logistic model to fit the curves and calculate EC50 values (JMP® 9 statistical software).

\section{Results and discussion \\ 3.1. Effect of ozone on $17 \beta$-estradiol (E2)}

A $50 \mu \mathrm{g} / \mathrm{L}$ E2 solution was ozonated according to the batch ozonation procedure described in Section 2.1 to achieve an applied dose of $50 \mu \mathrm{g} / \mathrm{L} \mathrm{O}_{3}$. After SPE concentration, the HPLC chromatograms show that no E2 or ozonation by-products were detected at the wavelength of analysis (Fig. 1) suggesting degradation of E2 to a level below the limit of detection (LOD) after $\mathrm{O}_{3}$ treatment.

\subsection{Effect of ozone on $17 \alpha$-ethinylestradiol (EE2)}

Solutions containing 50 and $500 \mu \mathrm{g} / \mathrm{L} \mathrm{EE} 2$ were ozonated using 50 and $500 \mu \mathrm{g} / \mathrm{L} \mathrm{O}_{3}$, respectively, at pH 5.3 (unadjusted RO water). After SPE concentration, the HPLC chromatograms show that the EE2 was undetected (Fig. 2A and B). Two ozonation byproduct peaks were detected with HPLC retention times of 4.9 and $5.3 \mathrm{~min}$. The same 2 peaks were consistently detected regardless of EE2 concentration $(50 \mu \mathrm{g} / \mathrm{L}-$ Fig. $2 \mathrm{~A}$ and $500 \mu \mathrm{g} / \mathrm{L}-$ Fig. $2 \mathrm{~B}$ ) suggesting that their formation is not dependent on the initial EE2 concentration that is ozonated. However, the ratio of peak 1:peak 2 was almost 10 times smaller at the lower initial concentration of EE2 ( $50 \mu \mathrm{g} / \mathrm{L} \mathrm{vs.} 500 \mu \mathrm{g} / \mathrm{L})$ which suggests that peak 1 may be secondary to the formation of peak 2 . Similar experiments were conducted in EE2 solutions with pH levels adjusted to both low (Fig. $3 \mathrm{~A}-\mathrm{pH} 3$ ) and high (Fig. 3B $-\mathrm{pH} 8$ ) values. The HPLC profiles reveal incomplete removal of EE2 at both $\mathrm{pH}$ conditions. Two by-product peaks with similar retention times as described at $\mathrm{pH} 5.3$ were detected, with additional small peaks visible in the chromatogram after $\mathrm{O}_{3}$ addition at $\mathrm{pH}$ 8. These results suggest that the $\mathrm{pH}$ plays an important role in the

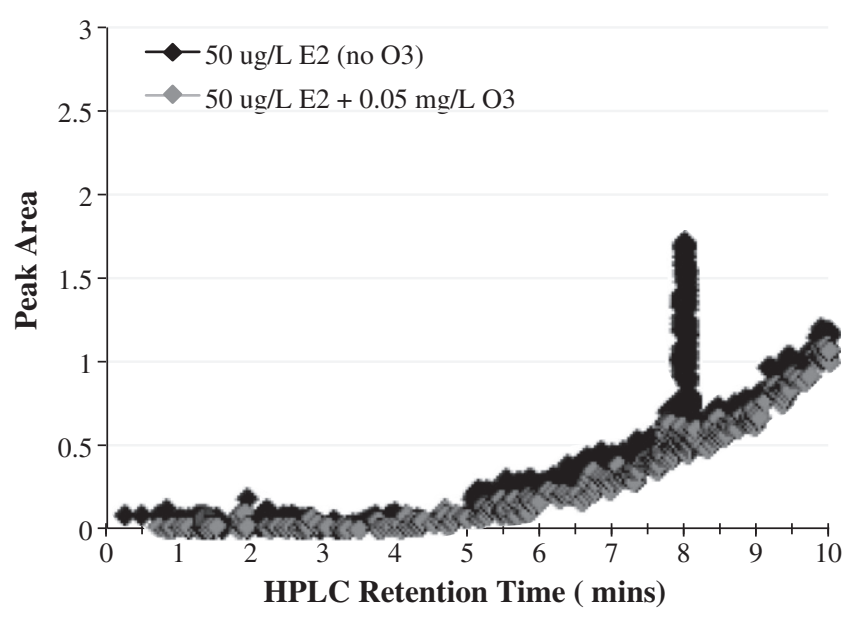

Fig. 1. Effect of ozone $\left(\mathrm{O}_{3}\right)$ on $17 \beta$-estradiol (E2) in reverse osmosis water at pH 5.3 as determined by HPLC-DAD analysis $\left(50 \mu \mathrm{g} / \mathrm{L} \mathrm{E} 2+50 \mu \mathrm{g} / \mathrm{L} \mathrm{O}_{3}\right)$. The samples were concentrated by a factor of 200 using solid phase extraction (SPE) prior to HPLC analysis. The E2 HPLC retention time was $8.1 \mathrm{~min}$.

removal of EE2 by $\mathrm{O}_{3}$. However, it does not affect the formation of the two primary by-product peaks resulting from the reaction of EE2 with ozone.

Interestingly, peak 1 was much smaller at both the low and high $\mathrm{pH}$ conditions when compared to the same EE2 and $\mathrm{O}_{3}$ concentration at pH 5.3 (Fig. 2B). The peak

A
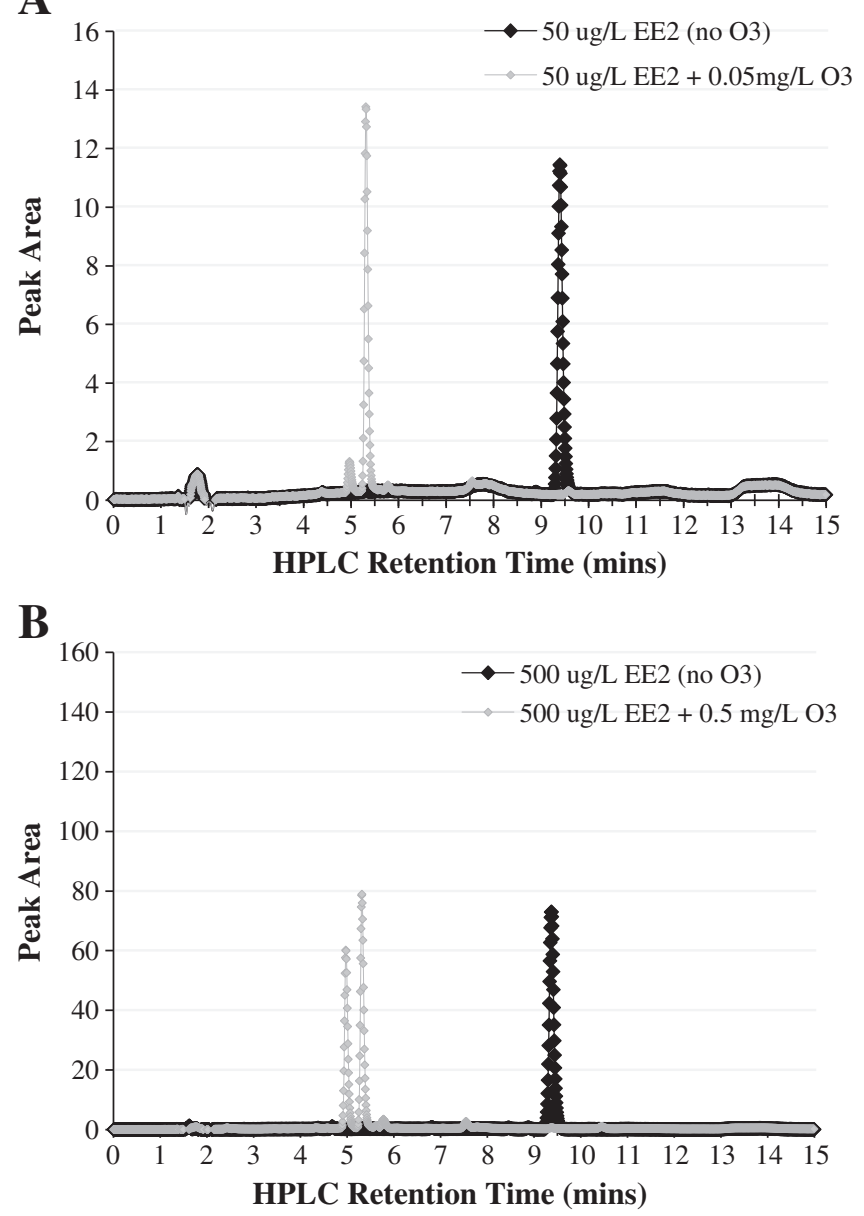

Fig. 2. Effect of ozone $\left(\mathrm{O}_{3}\right)$ on $17 \alpha$-ethinylestradiol (EE2) in reverse osmosis (RO) water at pH 5.3 as determined by HPLC-DAD analysis. The samples were concentrated by a factor of 200 using solid phase extraction prior to HPLC analysis. The retention times were 4.9 and $5.3 \mathrm{~min}$ for the two by-product peaks observed after ozonation; and $9.4 \mathrm{~min}$ for EE2. A low concentration of EE2 and $\mathrm{O}_{3}$ was tested $\left(\mathrm{A}: 50 \mu \mathrm{g} / \mathrm{L} \mathrm{EE} 2+50 \mu \mathrm{g} / \mathrm{L} \mathrm{O}_{3}\right)$ as well as a high concentration (B: $500 \mu \mathrm{g} / \mathrm{L} \mathrm{EE} 2+500 \mu \mathrm{g} / \mathrm{L} \mathrm{O}_{3}$ ). 
A
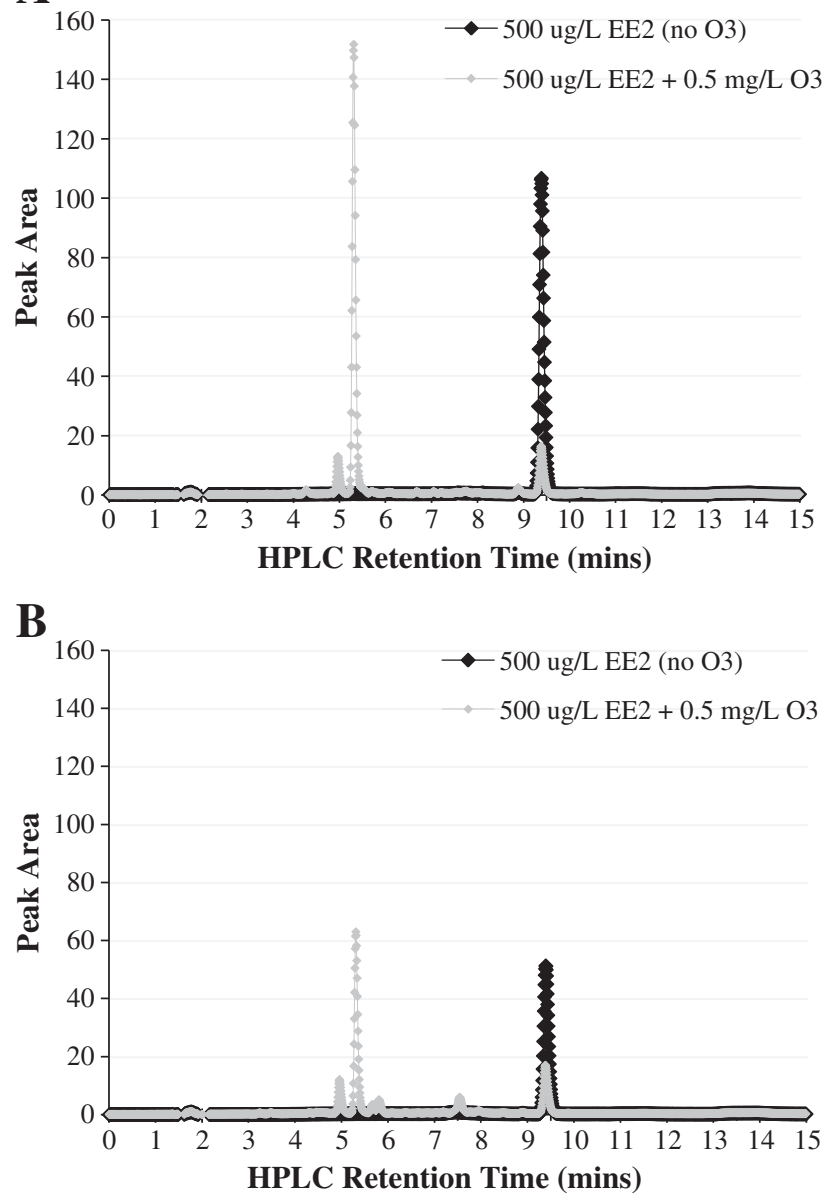

Fig. 3. Effect of ozone $\left(\mathrm{O}_{3}\right)$ on $17 \alpha$-ethinylestradiol (EE2) in reverse osmosis water at $\mathrm{pH}=3$ (A) and $\mathrm{pH}=8$ (B) as determined by HPLC-DAD analysis ( $500 \mu \mathrm{g} / \mathrm{L}$ EE2 + $500 \mu \mathrm{g} / \mathrm{L} \mathrm{O}_{3}$ ). The samples were concentrated by a factor of 200 using solid phase extraction prior to HPLC analysis. The reaction of EE2 with $\mathrm{O}_{3}$ resulted in the formation of 2 by-product peaks; the EE2 was not completely removed. The retention times were 4.9 and $5.3 \mathrm{~min}$ for the two main by-product peaks observed after ozonation; and $9.4 \mathrm{~min}$ for EE2. At the higher $\mathrm{pH}$ the recovery of analytes obtained via SPE was not as successful as at $\mathrm{pH} \leq 6$ and there were additional tiny by-product peaks observed on the HPLC chromatogram.

1:peak 2 ratio at both $\mathrm{pH} 3$ and $\mathrm{pH} 8$ was similar to the low EE2 concentration ozonated at pH 5.3 (Fig. 2A) reinforcing the idea that the formation of peak 1 is secondary to peak 2. This may be due to the slower reaction rate of $\mathrm{EE} 2$ with $\mathrm{O}_{3}$ at low $\mathrm{pH}$ and the increased formation of hydroxyl radicals $(\mathrm{OH} \cdot)$ at high $\mathrm{pH}$ due to $\mathrm{O}_{3}$ decomposition. Deborde et al. (2005) demonstrated that EE2 reacts slower with $\mathrm{O}_{3}$ at $\mathrm{pH}<5$. Therefore, it is expected that at $\mathrm{pH} 3$ the rate of reaction of $\mathrm{EE} 2$ with $\mathrm{O}_{3}$ will be less than at $\mathrm{pH}$ 5.3, potentially explaining why there was EE2 remaining after ozonation at the lower $\mathrm{pH}$. As $\mathrm{pH}$ increases it has been shown that autonomous ozone decomposition increases (Buffle et al., 2006; Yao and Haag, 1991; Zhang et al., 2006) resulting in the increased formation of hydroxyl radicals $(\mathrm{OH} \cdot)$. Since $\mathrm{OH} \cdot$ is a stronger oxidant than $\mathrm{O}_{3}$ but less selective to EE2 (Lee and von Gunten, 2009), this may have caused less EE2 removal at the higher pH condition. At pH 5.3 (where EE2 was removed below the LOD after ozonation), the two by-product peaks were approximately equal in size, whereas at both low and high $\mathrm{pH}$ (where there was EE2 remaining after ozonation), peak 1 was much smaller than peak 2 . As discussed previously, it can be assumed that the formation of peak 1 is secondary to that of peak 2 and that both are a function of the reaction of EE2 with $\mathrm{O}_{3}$. Thus, the incomplete removal of EE2 after ozonation at the low and high $\mathrm{pH}$ conditions would result in peak 1 to be proportionately smaller than peak 2 .

\subsection{Identification of ozone by-products of EE2}

LC-MS analysis showed that the by-product peaks appear to consist of more than one compound each. Although this mixture of ozonated by-products of EE2 was mostly unresolved, $[\mathrm{M}-\mathrm{H}]^{-}$ions corresponding to two compounds with masses 302.1517 and $344.1628 \mathrm{u}$, respectively (mass accuracy $\leq 2.03 \mathrm{ppm}$ ) were identified. Both of the byproducts are muconic acid derivatives with open phenolic ring structures (Fig. 4B<smiles>C#C[C@]1(O)CC[C@H]2[C@@H]3CCc4cc(O)ccc4[C@H]3CC[C@]21C</smiles><smiles>C[C@]12C=CC[C@@H]1[CH][C@H]1CC/C(=C\C(=O)O)[C@@H]1CC2</smiles><smiles>C#C[C@]1(O)CC[C@H]2[C@@H]3CC/C(=C\C(=O)O)C(=CC(=O)O)[C@H]3CC[C@]21C</smiles>

Fig. 4. EE2 (A) and two of its ozonated by-products with a mass of $302 \mathrm{u}(\mathrm{B})$ and a mass of $344 \mathrm{u}(\mathrm{C})$ as identified with LC-MS analysis (APCI) and verified with deuterated EE2. It should be noted that the phenolic ring was open after ozonation, suggesting a potential decrease in estrogenic activity.

and $\mathrm{C}$ ). The deuterated congeners of each were also detected (mass accuracy $\leq 4.07 \mathrm{ppm}$ ), confirming the identified by-products. The by-product with a mass of $344 \mathrm{u}$ was the only identified compound of the several forming peak 2 . The formation of these by-products has been observed recently (in addition to four other compounds) during investigations of the reaction pathways of EE2 with $\mathrm{O}_{3}$ (Vieira et al., 2010). However, we believe this is the first time that the identities of these two byproducts ( 302 and $344 \mathrm{u}$ ) have been confirmed with the simultaneous ozonation of a deuterated EE2 compound. The fate of the phenolic ring in the by-products' structures is vital as a closed ring is thought to be directly linked to the binding of compounds to the estrogen receptor (ER) (Anstead et al., 1997). Thus, a disruption of the phenolic moiety of EE2 is expected to lower its estrogenicity. Although previous studies have predicted the chemical structures of several by-products of EE2 ozonation, only a few of them conducted the YES assay to investigate the simultaneous change in estrogenicity. These previous studies identified EE2 ozonation by-products with the phenolic moiety intact (suggesting unchanged estrogenic activity); however, their YES assay results showed reduced estrogenicity (Guedes Maniero et al., 2008; Lee et al., 2008).

\subsection{Estrogenicity of parent compound and by-products}

Using the YES assay, we determined the estrogenic activity of EE2 before and after its reaction with $\mathrm{O}_{3}$ as well as the estrogenicity of each detected ozone by-product

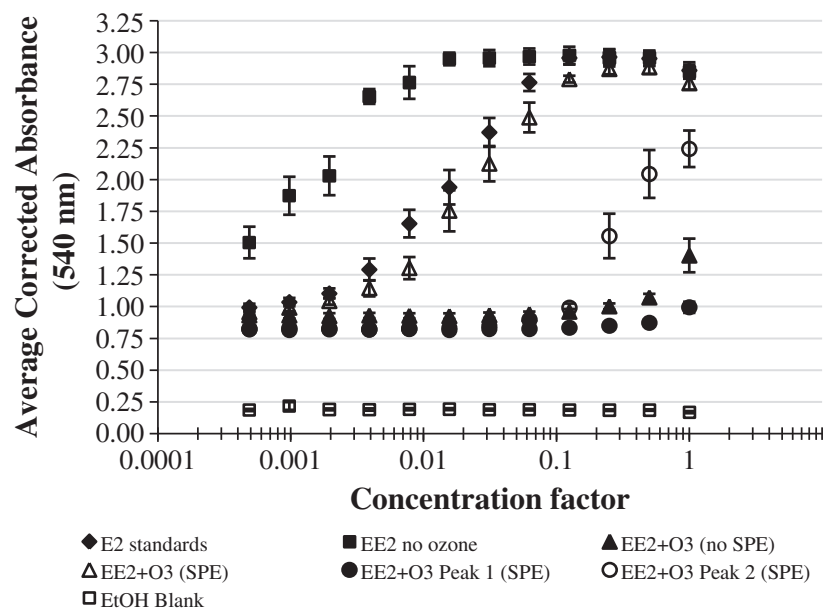

Fig. 5. Estrogenic dose-response using the YES assay (after 4 days incubation) of E2, EE2 before and after reaction with $\mathrm{O}_{3}$, as well as individual ozonated by-product peaks collected as fractions (peak 1 and peak 2). Waters after ozonation or containing each peak were concentrated 200 times by solid phase extraction (SPE). Data represent the average corrected absorbance \pm SEM from plate replicates $(E 2, n=13$; EE2 and $\mathrm{EE} 2+\mathrm{O}_{3}, \mathrm{n}=6$; peaks, $\mathrm{n}=7$; $\mathrm{EtOH}, \mathrm{n}=6$ ). 

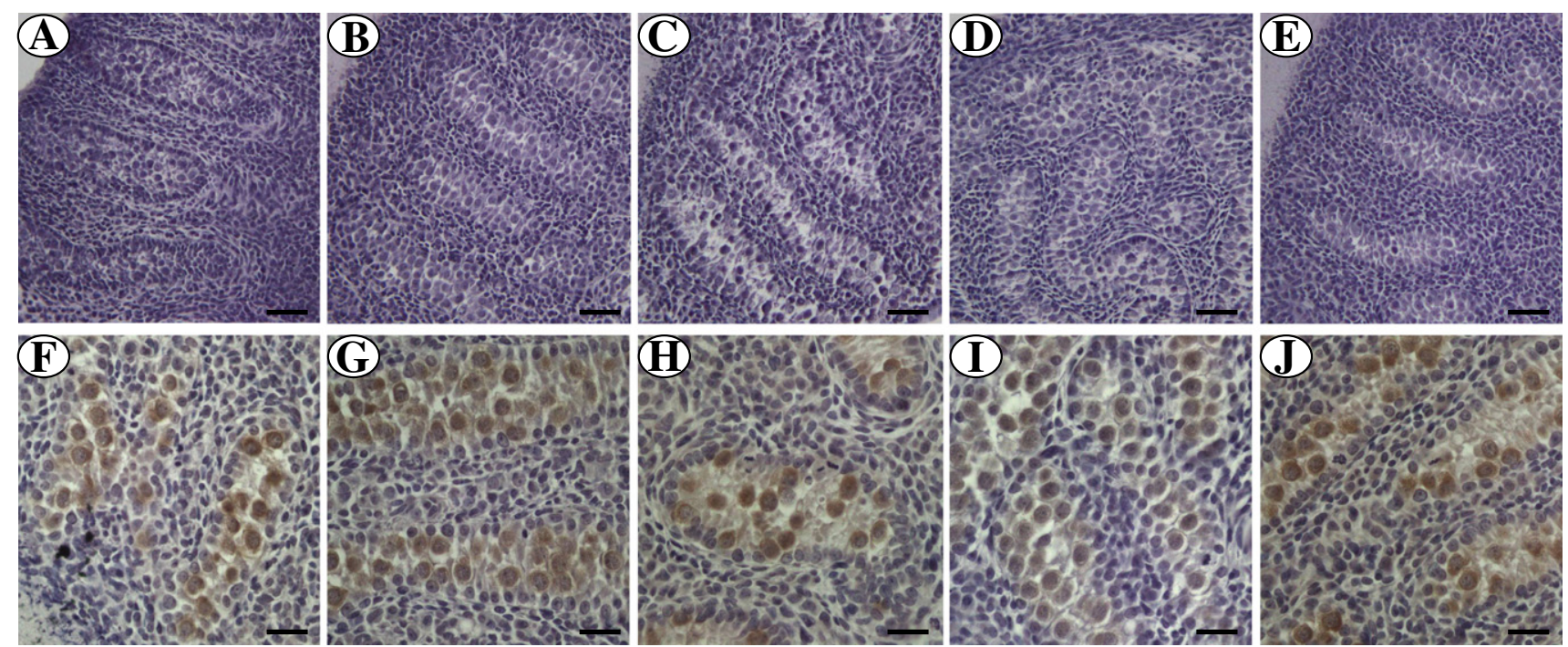

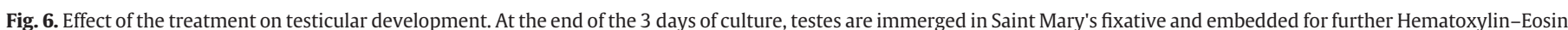

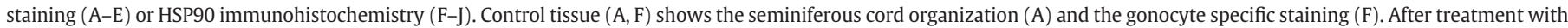

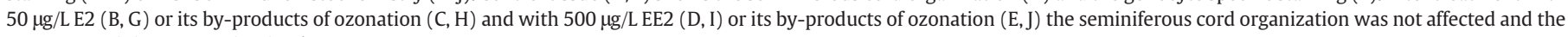
gonocyte staining was maintained. Bars represent $50 \mu \mathrm{m}$.

peak. Due to low estrogenicity, it was necessary to concentrate the post-ozonation samples (including the by-product peaks collected as fractions) 200 times via SPE. After 4 days of incubation, all samples were plotted alongside the dose-response curve of the E2 standards and the EtOH blanks against the dilution factor of each initial sample; undiluted samples were placed in the first well of each row and successive dilutions (1:2) were done across the remaining 11 wells in the row (Fig. 5). The EE2 sample $(500 \mu \mathrm{g} / \mathrm{L}$ initial concentration) tested shows an estrogenic response; however, after reaction with $500 \mu \mathrm{g} / \mathrm{L} \mathrm{O}_{3}$ there was a significant decrease in estrogenicity with a response only detected for the undiluted sample in well 1 . Only after the ozonated EE2 sample was concentrated 200 times by SPE was the characteristic sigmoidal dose-response curve observed demonstrating an approximate 1-log reduction in estrogenic response compared to the untreated EE2. This suggests that the estrogenicity of the EE2 solution was not completely removed after ozonation but was greatly reduced (by a factor of approximately 2000), which supports the hypothesis that by-products

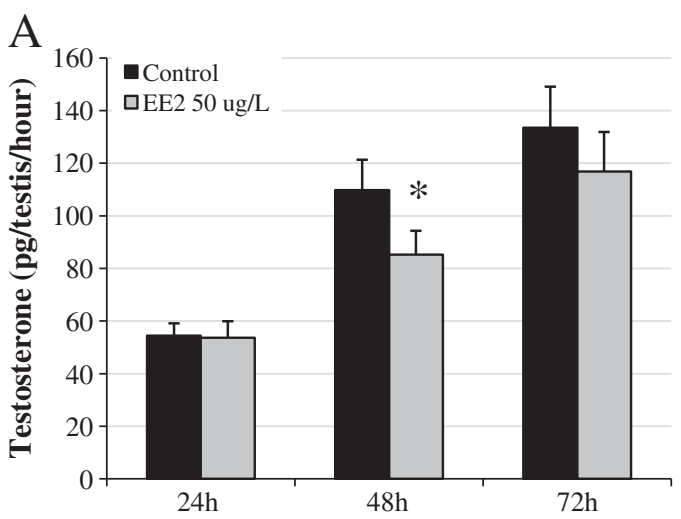

B
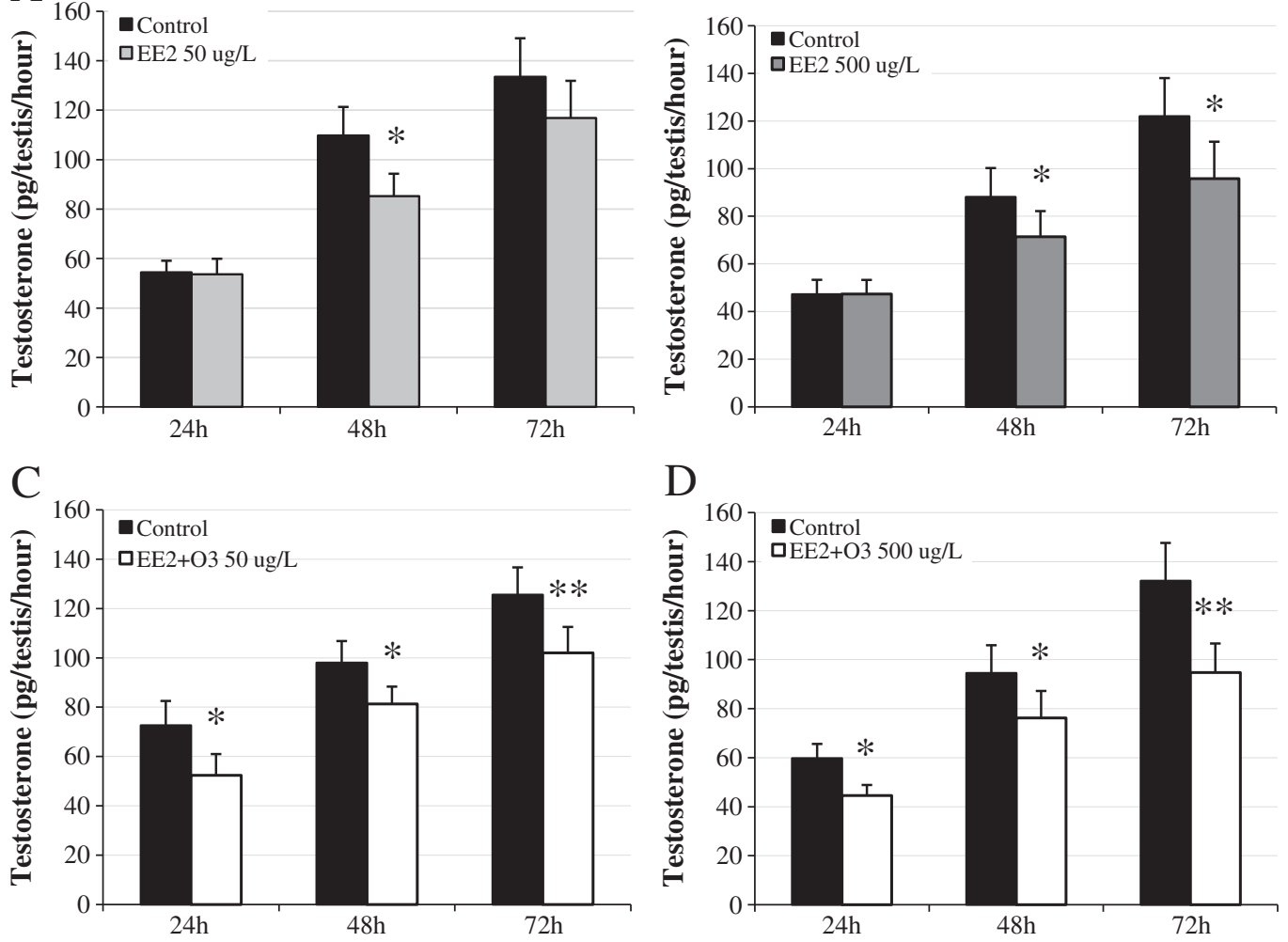

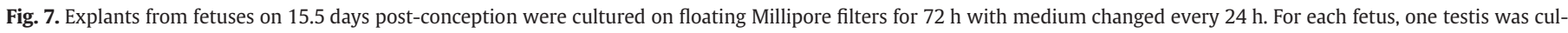

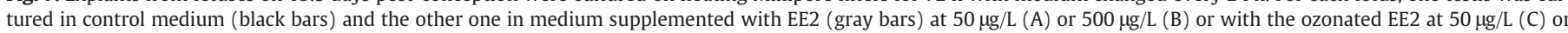
$500 \mu \mathrm{g} / \mathrm{L}(\mathrm{D})$. Values are mean \pm SEM from 9 cultures. ${ }^{*} p<0.05,{ }^{* *} p<0.01$ in the Bonferroni post-hoc tests comparing with the corresponding control value. 
with open phenolic ring structures have lower affinity for the ER. When the two main ozonated EE2 by-product peaks were concentrated 200 times there was no estrogenic response by peak 1 but a weak response induced by peak 2 that was lower than that of the overall ozonated EE2 sample. This suggests that the compounds forming peak 2 play a larger role than those in peak 1 in the estrogenic activity remaining after the ozonation of water containing EE2. Since the by-product with a MW of $344 \mathrm{~g}^{\mathrm{mol}} \mathrm{m}^{-1}$ was the most prominent and only identified compound in peak 2, it can be assumed that this by-product exerted the majority of the remaining estrogenic activity of all the EE2 ozonation by-products formed. The same dilutions of the ozonated samples were tested for antagonism using a $1 \times 10^{-8} \mathrm{M} \mathrm{E2}$ standard in each well. No significant antagonistic effect was observed (Supplemental Fig. 2).

\subsection{Toxicity of parent compound and by-products}

In order to assess the toxicity of the EE2 ozonation by-products, we used an organ culture system that replicates ex vivo the in vivo rat fetal development (Livera et al. 2006). This system has previously been used in rats (Chauvigne et al., 2009; Delbes et al., 2007) and humans (Lambrot et al., 2009) to assess the impact of endocrine disruptors on testicular development. Because windows of sensitivity to estrogen exposure during rat fetal testis development have been described previously (Delbes et al., 2007), we chose to investigate the impact of the ozonation by-products in a very sensitive period of development, i.e., at $15.5 \mathrm{dpc}$

\subsubsection{Impact on testicular development}

To test the effect of the various compounds and treatments on testicular development, we cultured $15.5 \mathrm{dpc}$ rat testes for 3 days ex vivo in media prepared with water containing E2 or EE2 before and after ozone treatment at pH 5.3. Testes were fixed at the end of the 3 days of culture and sections were observed under a light microscope after Hematoxylin-Eosin staining (Fig. 6A-E). As previously described (Livera et al., 2006), testes grow ex vivo similarly to in vivo when cultured in control media, exhibiting the proper seminiferous cord organization (Fig. 6A). After treatment with $50 \mu \mathrm{g} / \mathrm{L}$ of E2 (Fig. 6B) or $500 \mu \mathrm{g} / \mathrm{L}$ of EE2 (Fig. 6D), the seminiferous cord organization was not affected, suggesting that the treatments did not perturb global testis development The same was observed after treatment with ozonated waters containing $50 \mu \mathrm{g} / \mathrm{L} \mathrm{E2}$ (Fig. 6C) or $500 \mu \mathrm{g} / \mathrm{L} \mathrm{EE2} \mathrm{(Fig.} \mathrm{6E).} \mathrm{The} \mathrm{gonocyte} \mathrm{specific} \mathrm{staining} \mathrm{for} \mathrm{HSP90} \mathrm{was} \mathrm{ob-}$ served for the same samples (Fig. 6G-J) and was comparable to the control (Fig. 6F), suggesting that the germ cells were not affected by any treatment. To our knowledge, only in vivo gestational exposures to EE2 have been previously reported to show smaller seminiferous cords and Leydig cell hyperplasia but only after 7 days of exposure to minimum of $0.02 \mathrm{mg} / \mathrm{kg} /$ day in mice (Yasuda et al., 1985).

\subsubsection{Impact on steroidogenesis}

To test the impact of the various compounds on fetal testosterone secretion, testosterone was measured in the culture media every $24 \mathrm{~h}$ for 3 days. Throughout the culture period, testosterone production increased significantly, indicating that the tissues were developing properly (Fig. 7). By comparing testosterone production over time from testes cultured in media prepared with RO water containing EtOH and treated with 0,50 or $500 \mu \mathrm{g} / \mathrm{L}$ of ozone (controls as outlined in Table 1), no significant impact was observed (black control bars in Fig. 7), suggesting that ozonated water alone does not affect fetal steroidogenesis in the organ culture system. It was determined that the presence of $50 \mu \mathrm{g} / \mathrm{L}$ of E2 (with and without ozone treatment) did not affect steroidogenesis (data not shown) which is in accordance with previous studies showing a negative impact of E2 only at higher concentrations $\left(10^{-6} \mathrm{M}, \sim 250 \mu \mathrm{g} / \mathrm{L}\right)$ (Delbes et al., 2007; Lassurguère et al., 2003).

The impact of the presence of EE2 on testosterone production over time was measured using a 2 way ANOVA analysis. In every condition (Fig. 7), both time and treatment had a significant interaction and effect. Testes from $15.5 \mathrm{dpc}$ fetuses cultured for 3 days in the presence of $50 \mu \mathrm{g} / \mathrm{L}$ of EE2 exhibited a small but significant decrease in testosterone production after $48 \mathrm{~h}$ (Fig. $7 \mathrm{~A}$ ) that was still observed, but was not significant after $72 \mathrm{~h}$. When the testes were cultured in the presence of $500 \mu \mathrm{g} / \mathrm{L}$ of EE2, a time-dependent decrease in testosterone production was observed with a significant reduction after 48 and $72 \mathrm{~h}$ (Fig. 7B). Testes exposed to $50 \mu \mathrm{g} / \mathrm{L}$ (Fig. 7C) or $500 \mu \mathrm{g} / \mathrm{L}$ (Fig. 7D) of ozonated EE2 showed a significant decrease in testosterone production from $24 \mathrm{~h}$ to $72 \mathrm{~h}$. It is interesting to note that although testosterone production was not affected by the EE2 treatment at $24 \mathrm{~h}$ (Fig. 7A and B), exposure to the ozonated EE2 induced a significant reduction at this and subsequent time points (Fig. 7C and D) suggesting that these products are more toxic than the parent compound. Interestingly, these results show for the first time that exposure to EE2 inhibited fetal testosterone production at a concentration where E2 did not $(50 \mu \mathrm{g} / \mathrm{L}$ ), suggesting a higher inhibitory potency of EE2 compared to E2. More importantly, it was demonstrated that ozonation cannot eliminate the EE2 inhibitory effect on steroidogenesis and that the by-products formed may even negatively impact testosterone production faster. Considering our YES assay results (Section 3.4) suggesting that the ozonated EE2 by-products contained in peak 2 have estrogenic activity, it is hypothesized that these by-products are responsible for binding to the ER present in fetal Leydig cells in 15.5 dpc rats (Fisher et al., 1997). The estrogenicity of both peaks being significantly reduced compared to EE2, the toxicity of the by-products may be in part due to action through ERs but other mechanisms need to be investigated. It should be noted that a significant dose dependent effect after ozonation of EE2 was not observed. At the low dose tested $\left(50 \mu \mathrm{g} / \mathrm{L} \mathrm{EE} 2+\mathrm{O}_{3}\right)$, the production of peak 2 was already at a maximum compared to the higher dose (500 $\left.\mathrm{\mu g} / \mathrm{L} \mathrm{EE} 2+\mathrm{O}_{3}\right)$ suggesting that peak 1 played a comparatively minimal role in the toxicity of the by-products.

\section{Conclusions}

Overall, this study illustrates that the removal of EE2 below the LOD via reaction with ozone results in the formation of by-products possessing less estrogenic activity (as assessed by the YES assay) than the parent compound. However, this cannot be used as an indicator of toxicity, as the ozonated EE2 demonstrated a greater negative impact on testosterone secretion by fetal rat testes. Thus, when implementing ozone as a water treatment strategy for removal of recalcitrant compounds such as EE2, the disappearance of the parent compound should not be the sole concern. The by-products created and their characteristics relative to the parent compound must also be considered.

Supplementary materials related to this article can be found online at doi:10.1016/j.envint.2011.09.008

\section{Acknowledgments}

These studies were funded by grants from NSERC, Health Canada and CIHR with no competing financial interests. The authors would like to acknowledge Pedro Segura for his help with the identification of the by-products of EE2 ozonation.

\section{References}

Anstead GM, Carlson KE, Katzenellenbogen JA. The estradiol pharmacophore: ligand structure-estrogen receptor binding affinity relationships and a model for the receptor binding site. Steroids 1997;62:268-303.

Aravindakshan J, Gregory M, Marcogliese DJ, Fournier M, Cyr DG. Consumption of xenoestrogen-contaminated fish during lactation alters adult male reproductive function. Toxicol Sci 2004;81:179-89.

Bader H, Hoigné J. Determination of ozone in water by the indigo method. Water Res 1981;15:449-56.

Balsiger HA, de la Torre R, Lee W-Y, Cox MB. A four-hour yeast bioassay for the direct measure of estrogenic activity in wastewater without sample extraction, concentration, or sterilization. Sci Total Environ 2010;408:1422-9.

Buffle M-O, Schumacher J, Meylan Sb, Jekel M, von Gunten U. Ozonation and advanced oxidation of wastewater: effect of $\mathrm{O}_{3}$ dose, $\mathrm{pH}$, DOM and HO-scavengers on ozone decomposition and HO generation. Ozone: Sci Eng 2006;28:247-59.

Cavallucci S. Top 200: what's topping the charts in prescription drugs this year? Pharmacy Practice, Canadian Healthcare Network. http://wwwimshealthcanadacom/vgn/images/ portal/cit_40000873/13/31/8286270612-TOP200-07-finalpdf2007.

Cevasco A, Urbatzka R, Bottero S, Massari A, Pedemonte F, Kloas W, et al. Endocrine disrupting chemicals (EDC) with (anti)estrogenic and (anti)androgenic modes of action affecting reproductive biology of Xenopus laevis: II. Effects on gonad histomorphology. Comp Biochem Physiol C Toxicol Pharmacol 2008;147:241-51.

Chauvigne F, Menuet A, Lesne L, Chagnon M-C, Chevrier C, Regnier J-F, Angerer J Jegou B. Time- and dose-related effects of Di-(2-ethylhexyl) phthalate and its main metabolites on the function of the rat fetal testis in vitro. Environ Health Perspect 2009;117:515. [517].

Cicek N, Londry K, Oleszkiewicz JA, Wong D, Lee Y. Removal of selected natural and synthetic estrogenic compounds in a Canadian full-scale municipal wastewater treatment plant. Water Environ Res 2007;79:795-800.

Culty M. Gonocytes, the forgotten cells of the germ cell lineage. Birth Defects Res C Embryo Today 2009;87:1-26.

Deborde M, Rabouan S, Duguet JP, Legube B. Kinetics of aqueous ozone-induced oxidation of some endocrine disruptors. Environ Sci Technol 2005;39:6086-92.

Delbes G, Duquenne C, Szenker J, Taccoen J, Habert R, Levacher C. Developmental changes in testicular sensitivity to estrogens throughout fetal and neonatal life. Toxicol Sci 2007;99:234-43.

Esplugas S, Bila DM, Krause LGT, Dezotti M. Ozonation and advanced oxidation technologies to remove endocrine disrupting chemicals (EDCs) and pharmaceuticals and personal care products (PPCPs) in water effluents. J Hazard Mater 2007;149:631-42.

Fisher JS, Millar MR, Majdic G, Saunders PTK, Fraser HM, Sharpe RM. Immunolocalisation of oestrogen receptor- $\alpha$ within the testis and excurrent ducts of the rat and marmoset monkey from perinatal life to adulthood. J Endocrinol 1997;153:485-95.

Gomes RL, Scrimshaw MD, Lester JN. Determination of endocrine disrupters in sewage treatment and receiving waters. TrAC. Trends Anal Chem 2003:22:697-707.

Guedes Maniero M, Maia Bila D, Dezotti M. Degradation and estrogenic activity removal of 17[beta]-estradiol and 17[alpha]-ethinylestradiol by ozonation and $\mathrm{O}_{3} / \mathrm{H}_{2} \mathrm{O}_{2}$. Sci Total Environ 2008:407:105-15.

Howdeshell KL, Furr J, Lambright CR, Wilson VS, Ryan BC, Gray Jr LE. Gestational and lactational exposure to ethinyl estradiol, but not bisphenol $\mathrm{A}$, decreases androgen-dependent reproductive organ weights and epididymal sperm abundance in the male Long Evans hooded rat. Toxicol Sci 2008;102:371-82. 
Huber MM, Canonica S, Park G-Y, Von Gunten U. Oxidation of pharmaceuticals during ozonation and advanced oxidation processes. Environ Sci Technol 2003;37:1016-24.

Huber MM, Ternes TA, vonGunten U. Removal of estrogenic activity and formation of oxidation products during ozonation of 17 ethinylestradiol. Environ Sci Technol 2004;38:5177-86.

Huber MM, Gobel A, Joss A, Hermann N, Loffler D, McArdell CS, et al. Oxidation of pharmaceuticals during ozonation of municipal wastewater effluents: a pilot study. Environ Sci Technol 2005;39:4290-9.

Joss A, Keller E, Alder AC, Göbel A, McArdell CS, Ternes T, et al. Removal of pharmaceuticals and fragrances in biological wastewater treatment. Water Res 2005;39:3139-52.

Kolpin DW, Furlong ET, Meyer MT, Thurman EM, Zaugg SD, Barber LB, et al. Pharmaceuticals, hormones, and other organic wastewater contaminants in U.S. streams, 1999-2000: a national reconnaissance. Environ Sci Technol 2002;36:1202-11.

Lai KM, Scrimshaw MD, Lester JN. The effects of natural and synthetic steroid estrogens in relation to their environmental occurrence. Crit Rev Toxicol 2002;32:113.

Lambrot R, Muczynski V, Lecureuil C, Angenard G, Coffigny H, Pairault C, Moison D, Frydman R, Habert R, Rouiller-Fabre V. Phthalates impair germ cell development in the human fetal testis in vitro without change in testosterone production. Environ Health Perspect 2009;117:32. [36].

Lange A, Paull GC, Coe TS, Katsu Y, Urushitani H, Iguchi T, et al. Sexual reprogramming and estrogenic sensitization in wild fish exposed to ethinylestradiol. Environ Sci Technol 2009;43:1219-25.

Lassurguère J, Livera G, Habert R, Jégou B. Time- and Dose-Related Effects of Estradiol and Diethylstilbestrol on the Morphology and Function of the Fetal Rat Testis in Culture. Toxicol Sci 2003;73:160-9. S

Lee Y, von Gunten U. Oxidative transformation of micropollutants during municipal wastewater treatment: comparison of kinetic aspects of selective (chlorine, chlorine dioxide, ferrate(VI), and ozone) and non-selective oxidants (hydroxyl radical). Water Res 2009:44:555-66.

Lee Y, Escher BI, Von Gunten U. Efficient removal of estrogenic activity during oxidative treatment of waters containing steroid estrogens. Environ Sci Technol 2008;42:6333-9.

Livera G, Delbes G, Pairault C, Rouiller-Fabre V, Habert R. Organotypic culture, a powerful model for studying rat and mouse fetal testis development. Cell Tissue Res 2006;324: 507-21.

Metcalfe CD, Metcalfe TL, Kiparissis Y, Koenig BG, Khan C, Hughes RJ, et al. Estrogenic potency of chemicals detected in sewage treatment plant effluents as determined by in vivo assays with Japanese medaka (Oryzias latipes). Environ Toxicol Chem 2001;20:297-308.

Miège C, Choubert JM, Ribeiro L, Eusèbe M, Coquery M. Fate of pharmaceuticals and personal care products in wastewater treatment plants - conception of a database and first results. Environ Pollut 2009;157:1721-6.

Nakada N, Shinohara H, Murata A, Kiri K, Managaki S, Sato N, et al. Removal of selected pharmaceuticals and personal care products (PPCPs) and endocrine-disrupting chemicals (EDCs) during sand filtration and ozonation at a municipal sewage treatment plant. Water Res 2007;41:4373-82.

Petrovic M, Sole M, Lopez de Alda MJ, Barcelo D. Endocrine disruptors in sewage treatment plants, receiving river waters, and sediments: integration of chemical analysis and biological effects on feral carp. Environ Toxicol Chem 2002;21:2146-56.

Reungoat J, Macova M, Escher BI, Carswell S, Mueller JF, Keller J. Removal of micropollutants and reduction of biological activity in a full scale reclamation plant using ozonation and activated carbon filtration. Water Res 2010;44:625-37.

Routledge EJ, Sumpter JP. Estrogenic activity of surfactants and some of their degradation products assessed using a recombinant yeast screen. Environ Toxicol Chem 1996;15: 241-8.

Schwarzenbach RP, Escher BI, Fenner K, Hofstetter TB, Johnson CA, von Gunten U, et al. The challenge of micropollutants in aquatic systems. Science 2006;313:1072-6.

Sharpe RM, Skakkebaek NE. Are oestrogens involved in falling sperm counts and disorders of the male reproductive tract? Lancet 1993;341:1392-6.

Ternes TA. Occurrence of drugs in German sewage treatment plants and rivers. Water Res 1998;32:3245-60.

Ternes TA, Kreckel P, Mueller J. Behaviour and occurrence of estrogens in municipal sewage treatment plants - II. Aerobic batch experiments with activated sludge. Sci Total Environ 1999a;225:91-9.

Ternes TA, Stumpf M, Mueller J, Haberer K, Wilken RD, Servos M. Behavior and occurrence of estrogens in municipal sewage treatment plants - I. Investigations in Germany, Canada and Brazil. Sci Total Environ 1999b;225:81-90.

Ternes TA, Stuber J, Herrmann N, McDowell D, Ried A, Kampmann M, et al. Ozonation: a tool for removal of pharmaceuticals, contrast media and musk fragrances from wastewater? Water Res 2003;37:1976-82.

Vieira KM, Nascentes CC, Augusti R. Ozonation of ethinylestradiol in aqueous-methanolic solution: direct monitoring by electrospray ionization mass spectrometry. J Braz Chem Soc 2010;21:787-94.

Vos JG, Dybing E, Greim HA, Ladefoged O, Lambré C, Tarazona JV, et al. Health effects of endocrine-disrupting chemicals on wildlife, with special reference to the European situation. Crit Rev Toxicol 2000;30:71-133.

Yao CCD, Haag WR. Rate constants for direct reactions of ozone with several drinking water contaminants. Water Res 1991;25:761-73.

Yasuda Y, Kihara T, Tanimura T, Nishimura H. Gonadal dysgenesis induced by prenatal exposure to ethinyl estradiol in mice. Teratology 1985;32:219-27.

Zhang X, Chen P, Wu F, Deng N, Liu J, Fang T. Degradation of $17 \alpha$-ethinylestradiol in aqueous solution by ozonation. J Hazard Mater 2006;133:291-8. 